\begin{abstract}
The stone scorpionfish (Scorpaena mystes) is common throughout the Gulf of California in Mexico. Because little information is available regarding the basic biological characteristics of this species and because commercial demand for it is increasing, the need for studies of population dynamics is urgent. We sampled 233 stone scorpionfish (117 males and 116 females) in the Gulf of California from May 2015 through April 2016 to estimate age and individual growth. Total lengths (TL) ranged between 15.3 and $35.5 \mathrm{~cm}$ for males and between 19.0 and $44.5 \mathrm{~cm}$ for females. Results from analysis of the edge types of otoliths (opaque and translucent) indicate an annual periodicity in the formation of annuli in sagittae. Ages of stone scorpionfish ranged from 2 to 10 years for males and from 3 to 15 years for females. Estimates for the parameters of the von Bertalanffy growth function were 34.76 and $48.22 \mathrm{~cm}$ TL for asymptotic length, $0.202 /$ year and $0.135 /$ year for growth coefficient, and -1.28 and -0.80 years for theoretical age at length zero for males and females, respectively. This study resulted in the first estimates of age and individual growth of stone scorpionfish, information that is essential for evaluation and management of this important fishery resource.
\end{abstract}

Manuscript submitted 14 May 2020. Manuscript accepted 15 October 2020. Fish. Bull. 118:324-328 (2020).

Online publication date: 29 October 2020. doi: 10.7755/FB.118.4.2

The views and opinions expressed or implied in this article are those of the author (or authors) and do not necessarily reflect the position of the National Marine Fisheries Service, NOAA.

\section{Age and growth of stone scorpionfish (Scorpaena mystes) from the Gulf of California in Mexico}

\author{
Ulianov Jakes-Cota (contact author)' \\ Arturo Tripp-Valdez ${ }^{1}$ \\ Marisol Arce-Acosta ${ }^{1}$ \\ Francisco Omar López-Fuerte ${ }^{2}$
}

Email address for contact author: ujakesc@gmail.com

${ }^{1}$ Departamento de Pesquerías y Biología Marina Centro Interdisciplinario de Ciencias Marinas Instituto Politécnico Nacional

Avenida Instituto Politécnico Nacional s/n

Colonia Playa Palo de Santa Rita

Apartado Postal 592

23096 La Paz, Baja California Sur, Mexico
The stone scorpionfish (Scorpaena mystes) is commonly found throughout the Gulf of California in Mexico, with a distribution in the eastern Pacific Ocean that extends from southern California to Chile, including offshore islands (Butler et al., 2012). This demersal species occurs in shallow waters and seaweed-covered reefs as well as in open, sandy areas to depths of $85 \mathrm{~m}$. It is considered an opportunistic predator and feeds mainly on crustaceans and small fish (Butler et al., 2012). Adults reach sizes up to $51 \mathrm{~cm}$ in total length (TL) (Robertson and Allen, 2015).

The meat of stone scorpionfish is considered to be of excellent quality and has high commercial value; as a result, this species has become an important fishery resource (Jakes-Cota et al., 2017). Historically, however, this species has not been sought after commercially because venom glands located along the spines of the fins can cause painful injuries and severe respiratory disorders (Poss, 1995); it has long been a secondary priority species in the artisanal fishery in the Gulf of California. Since 2012, decreases in the catches of other species of high commercial value, such as the Pacific red snapper (Lutjanus peru) and yellowtail jack (Seriola lalandi), caused an increase in price and capture volume of the stone scorpionfish, driving this species into the commercial sector as a complementary, high-quality product.

Given the little amount of data available on the basic biological characteristics of this species and its recent commercial exploitation in the region of the Gulf of California, there is an urgent need to document its basic life history (e.g., age, growth, mortality, and reproduction) and its population dynamics and to create a management protocol for this fishery resource. Age and individual growth should be included as key elements in every investigation focused on the rational exploitation of fishing resources (Beamish and Fournier, 1981). Prior to this study, the age and individual growth characteristics of stone scorpionfish were not available; therefore, the aims of our study were 1) to estimate age by using otoliths, 2) to 
estimate individual growth parameters, and 3) to test for significant differences in growth trajectories between males and females.

\section{Materials and methods}

Stone scorpionfish were collected once a month (21-22 individuals per month) in the artisanal fishery from May 2015 through April 2016. The fish were taken by spearing while using semiautonomous diving equipment (hookah), at depths up to $30 \mathrm{~m}$, at different fishing sites along $20 \mathrm{~km}$ of coastline south of the harbor of Santa Rosalia in Baja California Sur, Mexico. The standard length (SL) and TL were measured to the nearest millimeter, and the weight $(W)$ was recorded to the nearest $0.1 \mathrm{~g}$ for each individual. Sex was determined by using macroscopic examination of the gonads, and the exact binomial test was used to test differences in sex ratio. Pairs of sagittae were extracted, cleaned, and stored dry in plastic vials in the laboratory, and only the right otoliths were used for the analyses described in the rest of this section.

To describe the length-weight relationship, we used this equation:

$$
W=a T L^{\mathrm{b}},
$$

where $a=$ the intercept of the regression line; and

$b=$ the allometric coefficient, the slope of the regression line.

To describe the relationship independently for males and females with log-transformed length and weight data, we used this equation:

$$
\log W=a+b \log T L .
$$

The $a$ and $b$ parameters were estimated by using a simple linear regression analysis. A Student's $t$-test was performed to evaluate whether the $b$-value was significantly different from 3 , a value that indicates an isometric growth pattern (i.e., all body parts grow at approximately the same rate, and a fish has an unchanging body form throughout development). An analysis of covariance was used to test differences in $b$-values between males and females.

The otolith radius (OR) (Fig. 1) was measured under a stereoscope (Stemi SV11 ${ }^{1}$, Carl Zeiss AG, Oberkochen, Germany) at $3.2 \times$ magnification by using the imaging

\footnotetext{
${ }^{1}$ Mention of trade names or commercial companies is for identification purposes only and does not imply endorsement by the National Marine Fisheries Service, NOAA.
}

software AxioVision, vers. 4.6 (Carl Zeiss AG). The stereoscope was attached to a digital camera (AxioCam MRc 5, Carl Zeiss AG). The relationship between TL and OR was described by using a simple linear regression analysis.

Right otoliths were immersed in ethanol with the concave side down, and 2 independent readers counted the annuli once with a stereoscope, using reflected light against a dark background without prior knowledge of fish length or weight. Under reflected light, the nucleus (the core of the otolith) and the opaque bands appeared as light rings and the translucent bands appeared as dark rings (e.g., La Mesa et al., 2005, 2010; Bilgin and Çelik, 2009). The combination of an opaque band followed by a translucent band was considered to be an annulus, as has been done for other scorpionfish species (e.g., Massutí et al., 2000; La Mesa et al., 2005, 2010; Bilgin and Çelik, 2009). Annuli were counted from the nucleus toward the tip of the rostrum (the anterior projection of the otolith) along the same line (Fig. 1). The precision between readers was evaluated by using the mean coefficient of variation (CV) and average percent error (APE). Values of 5.5\% for $\mathrm{APE}$ and of $7.6 \%$ for $\mathrm{CV}$ have been considered adequate in many aging studies (Campana, 2001).

To validate the periodicity of the formation of opaque and translucent bands and to assign a unit of time (e.g., years) to the counted annuli, edge type analysis was used. For this analysis, the edge type of each otolith was recorded as either opaque or translucent, and, for each month, the percentages of opaque edges and of translucent edges in the total number of otoliths analyzed was plotted. 
The von Bertalanffy growth function was fitted to length-at-age data to estimate individual growth:

$$
L_{\mathrm{t}}=L_{\infty}\left(1-e^{-\mathrm{k}\left(\mathrm{t}-\mathrm{t}_{0}\right)}\right),
$$

where $L_{\mathrm{t}}=$ the length (TL, in centimeters) at age $t$;

$L_{\infty}=$ the asymptotic length;

$k=$ the growth coefficient; and

$t_{0}=$ the theoretical age at length zero.

Additionally, a likelihood ratio test (Kimura, 1980), also known as the likelihood ratio chi-square test, was applied to test for differences between males and females in parameters of individual growth.

\section{Results}

During the study period, 233 stone scorpionfish (117 males and 116 females) were sampled. No significant difference was found in the ratio of males to females when applying a 1:1 exact binomial test $(P>0.05)$. However, the number of males was lower than the number of females for the large fish ( $>30 \mathrm{~cm}$ TL). Overall, $70 \%$ of the sampled individuals ranged in size between 20 and $30 \mathrm{~cm}$ TL. The lengths of the males ranged from 15.3 to $35.5 \mathrm{~cm}$ TL (12.5-28.9 cm SL), with a mean length of $25.9 \mathrm{~cm}$ TL (SE 3.60). Comparatively, the lengths of the females ranged from 19.0 to $44.5 \mathrm{~cm}$ TL $(15.5-36.5 \mathrm{~cm}$ SL), with a mean length of $27.8 \mathrm{~cm}$ TL (SE 5.17). Weights ranged from 64 to $1033 \mathrm{~g}$ for males, with a mean weight of $406 \mathrm{~g}$ (SE 181), and from 119 to $1870 \mathrm{~g}$ for females, with a mean weight of $545 \mathrm{~g}$ (SE 385). The analysis of variance revealed significant differences in mean length $\left(F_{(1,231)}=10.67, P<0.05\right)$ and mean weight $\left(F_{(1,231)}=12.57\right.$, $P<0.05$ ) between males and females. Females were longer and heavier than males.

The length-weight relationship (Table 1) was not significantly different between males and females $\left(F_{(1,229)}=1.27\right.$, $P>0.05)$. The $b$-value of the length-weight relationship of males and females was not significantly different from 3 $(P>0.05)$, indicating an isometric growth pattern.
Otolith radius ranged between 2.5 and $5.6 \mathrm{~mm}$. The linear regression model developed to predict the relationship between OR and TL was as follows:

$$
T L=-3.53+3.910 R .
$$

The linear relationship between both variables was significant (coefficient of determination $\left[r^{2}\right]=0.79, P<0.05$ ).

The highest percentage of otoliths with opaque edges was recorded in August (81\%), followed by the percentage in December (65\%), and the highest percentages of otoliths with translucent edges were observed in February $(80 \%)$ and June $(68 \%)$. These results indicate that the periodicity of annulus formation is annual and that the formation of a new annulus begins with an opaque band in the months of August-September and ends with a translucent band in the months of May-July.

The detections of annuli were confirmed and annuli could be counted in $98 \%$ of the 233 otoliths analyzed. For the remaining $2 \%$ of otoliths, the annuli could not be counted because they were not visible. The ages of individual specimens ranged between 2 and 10 years for males and between 3 and 15 years for females. The most frequent ages ranged from 5 to 7 years $(63 \%)$ for males and from 4 to 6 years (74\%) for females. The values of $\mathrm{CV}$ and APE were 6.50 and 4.59 , respectively.

The parameters of the von Bertalanffy growth function for males and females and the growth curves that were fitted to length-at-age data are shown in Figure 2. Results of the likelihood ratio test indicate significant differences in parameters of the von Bertalanffy growth function between males and females $\left(\chi^{2}=1.89, P<0.05\right)$; females grew slower (indicated by a lower $k$ value) yet reached a greater maximum average length (indicated by a greater $L_{\infty}$ ) than males.

\section{Discussion}

In this study, the maximum length recorded for stone scorpionfish was $44.5 \mathrm{~cm}$ TL, which is comparable to the maximum length of $51 \mathrm{~cm}$ TL previously reported for this species (Robertson and Allen, 2015). In addition, individuals larger

\section{Table 1}

Estimates of the parameters from regression analysis of the length-weight relationship for male and female stone scorpionfish (Scorpaena mystes) caught in the Gulf of California in Mexico during May 2015-April 2016. The parameters are the intercept $(a)$ and slope $(b)$ of the regression line. $r^{2}=$ coefficient of determination; $\mathrm{CI}=$ confidence interval; $\mathrm{SE}=$ standard error of

\begin{tabular}{|c|c|c|c|c|c|c|c|}
\hline \multirow[b]{2}{*}{ Sex } & \multicolumn{3}{|c|}{$a$} & \multicolumn{3}{|c|}{$b$} & \multirow[b]{2}{*}{$r^{2}$} \\
\hline & Mean & SE & $95 \%$ CI & Mean & SE & $95 \%$ CI & \\
\hline Males & 0.0205 & 0.29136 & $0.0115-0.0365$ & 3.01 & 0.08975 & $2.84-3.19$ & 0.90 \\
\hline Females & 0.0159 & 0.18687 & $0.0109-0.0229$ & 3.09 & 0.05696 & $2.98-3.21$ & 0.93 \\
\hline
\end{tabular}
the mean. 


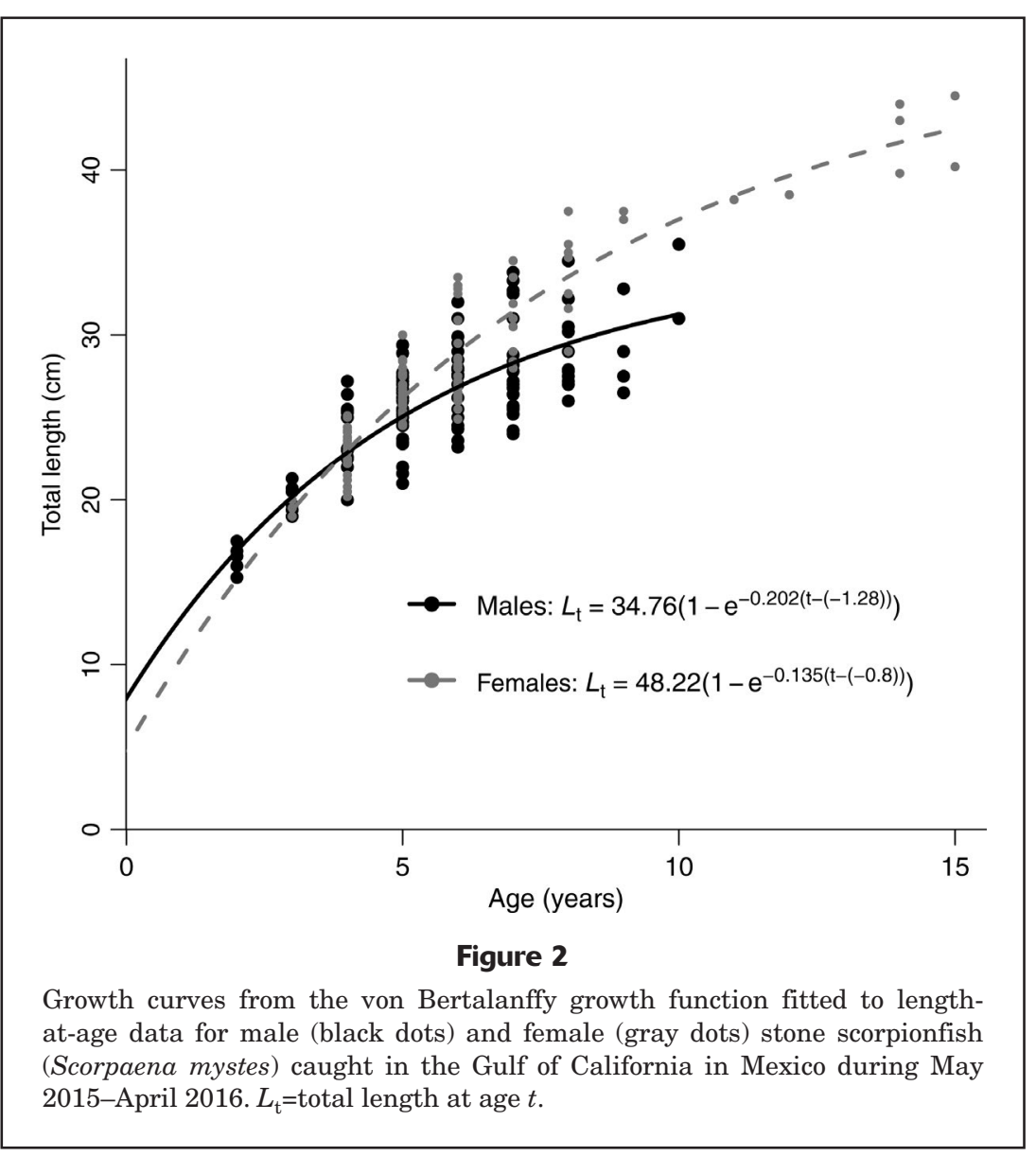

Results of the edge type analysis indicate that the periodicity of annulus formation in stone scorpionfish has an annual pattern. The highest percentages of opaque edges among all otoliths analyzed coincided with the highest condition factor values reported by Jakes-Cota et al. (2017) for stone scorpionfish for the months of August and September. This finding indicates that conditions for growth (e.g., high temperatures and high food availability) are favorable in our study area (Le Cren, 1951). In contrast, the highest percentages of translucent edges among all otoliths analyzed coincided with the lowest condition factor values reported by Jakes-Cota et al. (2017) for the months of February-June. This finding indicates conditions (e.g., low temperatures and scarce food) are unfavorable in our study area and may limit growth (Le Cren, 1951). The annual periodicity of annulus formation in otoliths has been reported for other scorpionfish species, such as the black scorpionfish (Bilgin and Çelik, 2009; Demirhan and Can, 2009; La Mesa et al., 2010), small red scorpionfish (Scarcella et al., 2011; Neves et al., 2015), Madeira rockfish (La Mesa et al., 2005), and blackbelly rosefish (Massutí et al., 2000).

Annuli were apparent in the otoliths of stone scorpionfish used in this study.

than $30 \mathrm{~cm}$ TL were scarce in our sampling, possibly a consequence of cumulative mortality in which larger and older individuals are removed by fishing or die naturally (Csirke, 1980).

The characteristics of the length-weight relationship indicate an isometric growth pattern for both males and females. Similar results were reported for this species even when males and females were not analyzed separately (Jakes-Cota et al., 2017). In contrast to these findings, it has been reported that other species of the genus Scorpaena, such as the black scorpionfish (S. porcus) (Bilgin and Çelik, 2009; Demirhan and Can, 2009), Madeira rockfish (S. maderensis) (La Mesa et al., 2005), and small red scorpionfish (S. notata) (Neves et al., 2015), commonly have positive allometric growth. However, as in our study of the stone scorpionfish and in studies of other scorpionfish species, such as the blackbelly rosefish (Helicolenus dactylopterus) (Massutí et al., 2000), results also indicate isometric growth.

The relationship between OR and TL of stone scorpionfish in our study was linear and statistically significant, indicating that these measurements have a relation of proportionality and that the OR may be a predictor of fish length. This relationship has been reported for other species of Scorpaena, such as the Madeira rockfish (La Mesa et al., 2005) and small red scorpionfish (Scarcella et al., 2011).
In general, translucent bands are slightly wider than the opaque bands, and as the number of annuli increased, the widths of both bands decreased. Both bands were clearly observed and distinguished, and it was relatively simple to count them, as evidenced by the low values of $\mathrm{CV}$ and APE; these low values indicate a high concordance between counts performed independently by readers and reflect consistency between observations. In this study, we found a significant relationship between the OR and length of fish, an annual pattern of annulus formation in otoliths, and a high precision in the counting of annuli between technicians. These results indicate that the otolith is a structure that can be used reliably in age estimation of stone scorpionfish.

This study is the first to report age and individual growth characteristics for stone scorpionfish. We found males up to 10 years old and females up to 15 years old, and we determined that individuals 4-7 years old composed the most abundant age class in our sample.

Individual growth characteristics were significantly different between males and females. In addition, our results indicate that females are larger, heavier, and older than males. This pattern of distinctive growth between males and females has been reported previously for the black scorpionfish (Bilgin and Çelik, 2009). However, it is also common that males reach lengths, 
ages, and $L_{\infty}$ that are greater than those of females, as has been observed for other species, such as the Madeira rockfish (La Mesa et al., 2005), small red scorpionfish (Neves et al., 2015), and blackbelly rosefish (Massutí et al., 2000). Results from our study indicate that males and females take approximately 10 years to reach a size of 30 and $35 \mathrm{~cm}$ TL, respectively, indicating that the stone scorpionfish is a slow-growing species, like most scorpionfish species.

The estimates of ages and individual growth rates reported from this study improve our knowledge of the stone scorpionfish. Information from this study can be used for stock assessment and management of a species of emerging fishing potential in the artisanal fishery of the Gulf of California.

\section{Acknowledgments}

The senior author and A. Tripp-Valdez would like to thank the Instituto Politécnico Nacional for funding through a grant from the Programa de Estímulos al Desempeño de los Investigadores. The senior author, A. Tripp-Valdez, and F. López-Fuerte are grateful for the support of the Sistema Nacional de Investigadores of the Consejo Nacional de Ciencia y Tecnología. D. Whitehead and S. Rousso reviewed the English version of this manuscript.

\section{Literature cited}

Beamish, R. J., and D. A. Fournier. 1981. A method for comparing the precision of a set of age determinations. Can. J. Fish. Aquat. Sci. 38:982-983. Crossref

Bilgin, S., and E. Ş. Çelik.

2009. Age, growth and reproduction of the black scorpionfish, Scorpaena porcus (Pisces, Scorpaenidae), on the Black Sea coast of Turkey. J. Appl. Ichthyol. 25:55-60. Crossref

Butler, J. L., M. S. Love, and T. E. Laidig.

2012. A guide to the rockfishes, thornyheads, and scorpionfishes of the Northeast Pacific, 185 p. Univ. Calif. Press, Berkeley, CA.

Campana, S. E.

2001. Accuracy, precision and quality control in age determination, including a review of the use and abuse of age validation methods. J. Fish Biol. 59:197-242. Crossref
Csirke, J.

1980. Introducción a la dinámica de poblaciones de peces. FAO Fish. Tech. Pap. 192, 82 p. FAO, Rome. [In Spanish.]

Demirhan, S. A., and M. F. Can.

2009. Age, growth and food composition of Scorpaena porcus (Linnaeus, 1758) in the southeastern Black Sea. J. Appl. Ichthyol. 25:215-218. Crossref

Jakes-Cota, U., A. Tripp-Valdez, and F. O. López-Fuerte.

2017. Length-weight relationship and relative condition factor of the stone scorpionfish Scorpaena mystes in the central area of the Gulf of California, Mexico. Hidrobiológica 27:127-129. Crossref

Kimura, D. K.

1980. Likelihood methods for the von Bertalanffy growth curve. Fish. Bull. 77:765-776.

La Mesa, M., G. La Mesa, and M. Micalizzi.

2005. Age and growth of madeira scorpionfish, Scorpaena maderensis Valenciennes, 1833, in the central Mediterranean. Fish. Res. 74:265-272. Crossref

La Mesa, M., G. Scarcella, F. Grati, and G. Fabi.

2010. Age and growth of the black scorpionfish, Scorpaena porcus (Pisces: Scorpaenidae) from artificial structures and natural reefs in the Adriatic Sea. Sci. Mar. 74:677-685. Crossref

Le Cren, E. D.

1951. The length-weight relationship and seasonal cycle in gonad weight and condition in the perc (Perca fluviatilis). J. Anim. Ecol. 20:201-219.

Massutí, E., B. Morales-Nin, and J. Moranta.

2000. Age and growth of blue-mouth, Helicolenus dactylopterus (Osteichthyes: Scorpaenidae), in the western Mediterranean. Fish. Res. 46:165-176. Crossref

Neves, A., V. Sequeira, A. R. Vieira, R. B. Paiva, and L. S. Gordo. 2015. Age and growth of small red scorpionfish, Scorpaena notata (Actinopterygii: Scorpaeniformes: Scorpaenidae), a common discard species from the Portuguese fishery. Acta Ichthyol. Piscat. 45:13-20. Crossref

Poss, S. G.

1995. Scorpaenidae. In Guía FAO para la identificación de especies para los fines de la pesca. Pacífico CentroOriental. Vol. 3. Vertebrados-parte 2 (W. Fischer, F. Krupp, W. Schneider, C. Sommer, K. E. Carpenter, and V. H. Niem, eds.), p. 1544-1564. FAO, Rome. [In Spanish.]

Robertson, D. R., and G. R. Allen.

2015. Shorefishes of the tropical eastern Pacific: online information system, vers. 2.0. Smithsonian Trop. Res. Inst., Balboa, Panama. [Available from website, accessed November 2019.]

Scarcella, G., M. La Mesa, F. Grati, and P. Polidori.

2011. Age and growth of the small red scorpionfish, Scorpaena notata Rafinesque, 1810, based on whole and sectioned otolith readings. Environ. Biol. Fish. 91:369. Crossref 